\title{
An analytical study of histological hazards estimation and comparison between cholecystitis and cholelithiasis by routine, mucin and lipid histochemistry procedures
}

\author{
Jyoti Prakash Pani ${ }^{1}$ and Sankarsan Pani ${ }^{2}$ \\ ${ }^{1}$ Anatomy Raigad Hospital and Research Center/Sir Nandkumar Tasgaonkar Institute of Medical Science and Research Center, Karjat, Navi Mumbai, India \\ ${ }^{2}$ Raigad Hospital \& Research Center/Sir Nandkumar Tasgaonkar Institute of Medical Science and Research Center, Karjat, Navi Mumbai, India
}

\begin{abstract}
The current study emphasizes on routine, mucin and lipid histochemistry procedures to estimate and compare histological hazards in diseased human stone filled and bacterial infections induced hypertrophied gall bladder. 100 normal \& $50(25+25)$ diseased human gallbladders having cholelithiasis and cholecystitis were chosen for conduction of this study. After proper processing, from each sample 3 slides were stained by H\&E stain, Combined PAS-AB stain \& Sudan Black B stain respectively for routine, mucin \& lipid histochemistry study. In routine histochemistry predominant histological alterations were estimated and found maximum epithelial discontinuity was $62.5 \%$ in cholelithiasis where as $59.09 \%$ in cholecystitis. In mucin histochemistry combine PAS-AB stain the supra-nuclear and infra-nuclear part of the epithelium showed intense brownish blue color suggestive of predominant Sulfomucin and sailomucin effect (91.91\% cases in cholelithiasis, $87.5 \%$ cases in cholecystitis). The result of lipid histochemistry indicated accumulation of phospholipids in epithelial cells predominantly in supranuclear region in cholelithiasis. (99.09\%) Scattered lipids were found in other cells and tissues in cholecystitis gall bladder. (76.76\%) The basic principle in gall stone formation is accumulation of lipids and hyper secretion of acidic mucin. Sulfomucin enzyme have major role in gall stone generation. Preliminary to it is the stage when cholecystitis occurs and it shows sailomucin effect. Blockage of mucin release can prevent gall stone formation in high risk patients or during high risk period. The compounds which can regulate sailylation and sulfation might help to inhibit gall stone formation and metastasis. This needs further study and entirely new therapeutic approach.
\end{abstract}

\section{Introduction}

Gallbladder carcinoma is found in up to $1.5 \%$ of cholecystectomy specimens of gall bladder diseases like cholecystitis and cholelithiasis. Gallbladder specimens are sent for routine histopathology, to rule out incidental gallbladder carcinoma. Cholecystectomy specimen's losses evidence of rare pathologies when send for histopathological reports such as premalignant benign lesions, carcinoma in medulla and early carcinomatous stage. To avoid such major mistakes every cholecystectomy specimen should be routinely examined histologically. Obese, multiparous females between 45 to 55 age ranges are predominant sufferer of cholecystitis and cholelithiasis, which is most common diseases, occurs in primate vertebrate \& human gall bladder. These diseases equally victimizes alcoholic males and kids [1]. In the last 25 years India and rest of the global countries of west and east produced high percentages of cholecystitis and cholelithiasis due to upraised consumption of lipofillous, heavy calorie and energetic drinks and fast foods and also increased intake of alcohol in clubs and parties [2,3]. Most common sign and symptoms seen in these diseases are peak with stabbing and throbbing type of pain in Murphy's point (+ve Murphy's sign) in right upper quadrant of abdomen, bilious vomiting, mild to moderate increase in temperature $\left(102-103^{\circ} \mathrm{F}\right)$, yellow discoloration of cornea and nail beds in late stage, severe loss of appetite and loss of weight, epigastric and right upper quadrant of abdomen pain which occurs in 30-60 minutes intervals after meals is frequently associated with gallstone disease. The diagnosis of chronic cholecystitis is made by the presence of biliary colic with evidence of gallstones on an imaging study. Cholecystitis (gall bladder inflammation) is not so disastrous and life threatening but in late stage it produces hazardous complications but Cholelithiasis (stone fill gall bladder) is an acute condition and it deserves urgent cholecystectomy intervention. Anatomy of normal gall bladder shows the fosse for the gallbladder in inferior surface of liver extends from the right end of the portahepatis to the inferior border of the liver [4]. It is 8 to $12 \mathrm{~cm}$ (3.5 to 4.5 inches) long and approximately $3.5 \mathrm{~cm}$ broad at its widest part and about 35 to $55 \mathrm{ml}$ in capacity this morphology differs from case to case [5]. The whole body of gall bladder anatomically divides into fundus, body and neck [6]. While the neck is continues as cystic duct $\&$ is marked by a constriction. From histological point of view the human gall bladder shows 4 layers and absence of muscularis mucosa in slide view through light microscopically observation [7]. It also shows mucosal layer, loose sub mucosa, muscle layer and adventitial (serosal) layer from medulla to cortex sequence. The wall of human gallbladder represents certain abnormal histological features in diseased cholecystitis and cholelithiasis condition. Most common disease which leads to surgical manueveration is cholelithiasis and cholecystitis. On an average 850,000 cholecystectomies are performed in India every year. Approximately $25 \%$ of the adult population is affected of cholecystitis in India. Percentages of bile calculus rose with age. $35 \%$ of adults over 45 years of age and $55 \%$ of those above age of

Correspondence to: Jyoti Prakash Pani, Raigad Hospital \& Research Center/Sir Nandkumar Tasgaonkar Institute of Medical Science \& Research Center, Raigad, Karjat, NaviMumbai, India, Tel: 8433668356; E-mail: jyotiprakash.pani35@gmail.com

Key words: Rokitansky Aschoff sinus, lymphoid proliferation, Sulfomucin

Received: March 22, 2017; Accepted: April 24, 2017; Published: April 27, 2017 

procedures

70 have biliary calculi and are calculated by medical survey in India. In the fertility period, the female male ratio is about $5: 1$, with the sex discrimination zips in the aged peoples. The causative agents which evoke preaccumulating factors to biliary calculus formation includes obesity, unusual fast food intake, alcohol consumption, diabetes mellitus, estrogen and progesterone level disruption in pregnancy, hemolytic diseases like hemophilia, and cirrhosis of liver. Past history of cholelithiasis disease elaborates that approximately $35 \%$ of sufferers initially diagnosed with having, but untreated for, bile gall calculus in late stage developed complications or recurrence of signs leading to surgical removal of gall bladder. The present study also emphasizes to compare occurrences of signs and symptoms between diseased and control [8-10].

\section{Review of literature}

Virchow R., in 1857 studied and researched human gall bladder fats in epithelium and observed fats can abnormally deposit in gall bladder epithelium [11]. Storey, Sheean studied and researched an improvised method of staining leukocyte granule with Sudan black B and stained diseased gall bladder mucosa with it. Finally, they observed the color of accumulated lipids in that region is ash grey [12]. Wall raff et al., researched human gall bladder mucosa \& observed fats in the human gallbladder mucosal epithelial surface in the patient with repeated inflammation of human gall bladder [13]. Hopwood et al., studied and researched diseased cholecystitis and inflamed human gall bladder and observed the presence of various fats in the wall of the human gall bladder with significant increment in the neutral fats in the sub mucosa in severe cholecystitis. A small part of these fats observed contained inflammatory cells and macrophages [14]. Stevens et al., studied 70 cholecystitis gall bladders for lipids in their epithelium and found discrete and scattered fats histologically [15]. Smith et al., researched and studied role of mucin in path physiology and formation of gall stone found in human \& other primate vertebrate mammals and found, the experimental mucosa epithelia is able to secrete altered mucus \& these secretory products interact with bile \& potentiate the cholesterol nucleating process also it progresses from the sludge to the production of bile calculus [16]. Hopwood et al., studied and researched fats in human gall bladder epithelia \& found ultra-structural changes in the human cholecystitis and they found some inflammatory changes along with large fatty deposits were visualized \& further it was found that the lipid deposits integrated and fused with mucus containing vesicles to form membrane bound complex structures delineated by a membrane and they designated those lipomucosomes along with it other tissues of the gall bladder wall also increase their fatty deposits [17]. Pearson et al., observed mucus glycoprotein in the human cholesterol gall stones [18]. Afdhal studied cholesterol crystal nucleation \& found the gall bladder mucosa plays a regulatory role in cholelithiasis as it promotes the nucleation of stones [19]. Jeffery GP et al., in 1991 studied and researched histological and immunohistochemical study of the gall bladder lesions in primary sclerosing cholangitis \& observed adequate amount of lymphoid follicles \& plasma cells within sub mucosa \& moderately to severe chronic inflammations were also observed along with it [20]. Badke et al., studied and researched histological changes in cholelithiasis affected inflamed gall bladder \& found inflammatory changes in some \& fibrotic changes in others [21]. Gilloteaux et al., studied and researched morphological aspect of diseased and inflamed human gall bladder in cholelithiasis and observed for production of stone glycoproteins are responsible through bile sludge [22]. Csendes et al., studied and researched histological findings of gallbladder mucosa in 95 control subjects and with asymptomatic gall bladder calculus and their observations suggested that chronic inflammatory changes can occur in the gall bladder mucosa prior to appearance of macroscopic stones [23]. Lee et al., studied and researched sulpho and sailo mucin content in gall bladder with brown pigment stones or combination stones. Gall bladder mucin itself has been recognized to play the important role in gall stones development. Despite the diverse mechanism of stone induction \& the differences in the stone composition there is quantitative increase in the epithelial sulpho mucin and mucus production before stone formation [24]. Hopwood et al., studied and researched fat in the human gall bladder mucosa through an immunohistochemistry study by light and electron microscopy and observed the distribution of fats in the epithelium of 70 cholecystitis inflamed and diseased human gall bladders. Neutral lipid was found at the base of the epithelial cells was $90 \%$ and at the apex of the epithelial cells $10 \%$ and in the underlying connective tissue [17]. Ganesh et al., studied and researched mucin histochemistry of stone containing gall bladder epithelium. They observed mucin play an important role in gall stone formation [25]. Smith et al., studied role of human gall bladder mucin in path physiology of gall stone in nucleation. Mucin, a high molecular weight glycoprotein secreted by human and mammalian gall bladder and biliary duct epithelium is a pronucleating agent [16]. Badke et al. studied and researched histological alterations in cholelithiasis inflamed and diseased human gall bladder \& found inflammatory changes in some \& fibrotic changes in others [21]. Csendes et al., studied and researched histological findings of human gallbladder mucosa in 95 control subjects and with asymptomatic cholelithiasis. Their observations suggested that chronic inflammatory changes can occur in the gall bladder mucosa prior to appearance of macroscopic stones [23]. Baylis High et al., studied and researched 70 cholecystitis gall bladders for fats in their epithelium and observed abnormal accumulation of fats can occur in cholecystitis epithelium [26]. Jeffery et al., studied histological and immunohistochemical study of the gall bladder lesions in primary sclerosing cholangitis \& observed adequate amount of lymphoid follicles \& plasma cells within sub mucosa of cholecystits gallbladder [20].

\section{Aim and objectives}

\section{Aim}

The aim of the present study is to compare and estimate the histological changes in the wall of human gallbladder in abnormal conditions such as cholelithiasis and cholecystitis with control.

\section{Objectives}

To compare and estimate percentages of histological hazards between control and diseased human gall bladder cholecystitis and cholelithiasis through specific approaches such as routine histochemistry, mucin histochemistry and lipid histochemistry.

\section{Material and methods}

100 normal \& $50(25+25)$ diseased human gallbladders having cholelithiasis and cholecystitis were chosen for conduction of this study. Male and female normal and diseased human gall bladder were used. The strains were homosapiens. The weight of both male and female were around 65 to $75 \mathrm{~kg}$ and the range of age was around 45 to 55 years. The tissues were labeled and subjected to histological processing. From each sample 9 slides were taken, out of which -3 slides were stained by haematoxylin \& eosin stain. 3 slides were stained by combined PASAB method. 3 slides were stained by Sudan Black B stain. In routine, mucin and lipid histochemistry predominant histological alterations 

procedures

were estimated and compared.

\section{Results}

In routine histochemistry overall and concern with all histological layers from inside out, predominant histological alterations were estimated and compared such as maximum and minimum epithelial discontinuity, epithelial dysplasia, honey comb shape epithelial distortion, sub epithelial hemorrhages, presence of goblet cells, absence of goblet cells, intact epithelia, eroded mucosa, maximum and minimum infiltration of lymphocytes, Rokytansky Aschoff Sinus, irregularity and gap in successive layers, multiple vessels distortion of all layers and infiltration of macrophages and plasma cells in all layers and overall average of all these histological hazards were calculated and compared viz. $62.5 \%$ in cholelithiasis, $59.09 \%$ in cholecystitis and $29.75 \%$ in control (histoprocessing error). In mucin histochemistry combine PAS-AB stain overall and concern with all histological layers from inside out, the supra-nuclear and infra-nuclear part of the epithelium with rest of the layers observed intense brownish blue and magenta color suggestive of significant Sulfomucin and no significant Sailomucin effect in cholelithiasis but no significant Sulfomucin and significant Sailomucin effect in cholecystitis and no significant both in control and overall average of all these histological findings were calculated and compared viz. $91.91 \%$ in cholelithiasis, $87.5 \%$ in cholecystitis and $42.75 \%$ in control. The result of lipid histochemistry with Sudan Black B stain overall and concern with all histological layers from inside out, indicated accumulation of phospholipids and scattered lipids predominantly in supranuclear region of epithelial cells and rest of the layer and average calculated in cholelithiasis $99.09 \%$, in cholecystitis $76.76 \%$ and in control $38.75 \%$ (Figure 1).

\section{Discussion}

In the current case control study an attempt is made to estimate and compare the overall histological alterations in cholelithiasis, cholecystitis and control human gall bladders by the evaluation of overall and average percentages of all histological hazards and other findings concerned with all histological layers by the application of routine histochemistry, mucin histochemistry and lipid histochemistry. We found the intensity and grade of appearances of such histological hazards and other findings gradually diminishes and reduces from cholelithiasis towards control. (Graph 1 given below). The main aims and objectives of this currents study is to estimate and compare overall percentages of histological hazards and other findings concern with all layer of diseased human gallbladder such as cholelithiasis, cholecystitis and control and the control samples observed minimal alterations

\section{Graph 1}

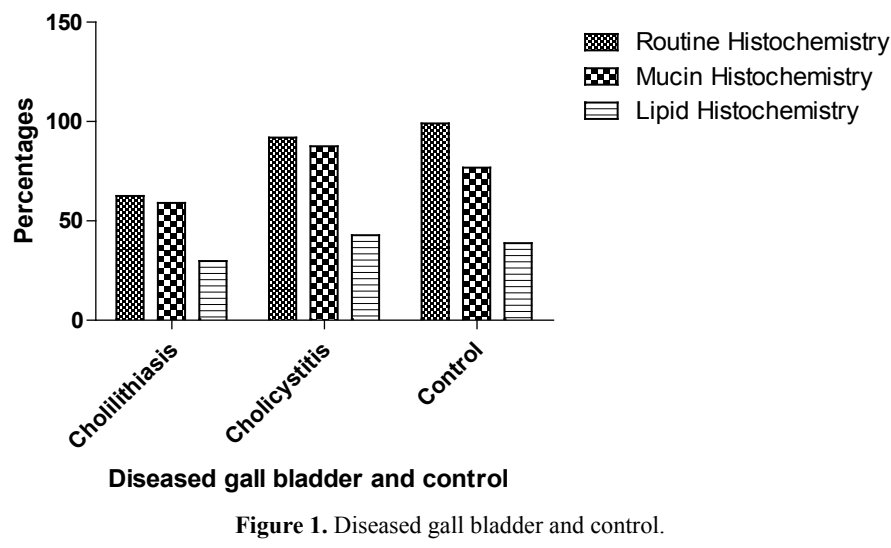

because of histoprocessing errors may be a by chance factor.

\section{Conclusion}

Cholecystitis is the beginning stage of stone formation prior to further stage cholelithiasis or already bile stone formed stage in human gall bladder wall because of bacterial binding (tomb effect) to supersaturated bile with cholesterol monohydrate crystals along with enucleating cholesterol monohydrate crystal and concentration of mucus glycoprotein's which ultimately interact with mucin, calcium and bilirubin is definitely a chain process. Control to cholecystitis towards cholelithiasis is a gradual pathway to reach end stage carcinoma gall bladder. The secretion of unnatural sulphomucins from epithelia of stone filled human gall bladder is the main cause of production of black pigment stones. The basic principle in gall stone formation is accumulation of lipids and hyper secretion of acidic mucin. Sulfomucin enzyme have major role in gall stone generation. Preliminary to it is the stage when cholecystitis occurs and it shows sailomucin effect. Blockage of mucin release can prevent gall stone formation in high risk patients or during high risk period. The compounds which can regulate sailylation and sulfation is aspirin which might help to inhibit gall stone formation and metastasis. This needs further study and entirely new therapeutic approach. If stone formation process is not prevented ultimately leads towards carcinoma gall bladder.

\section{Acknowledgement}

The author sincerely acknowledges Dr Sankarsan Pani for their financial and moral support.

\section{References}

1. Mohan H (2005) Extra Hepatic Biliary Apparatus-Gall bladder. Chapter 19 (5 $5^{\text {th }}$ Edn) Text Book of Pathology: 658-664.

2. Carey MC (1993) Pathogenesis of gallstones. Am J Surg 165: 410-419. [Crossref]

3. Sherlock S (1997) Diseases of the liver and biliary system. Blackwell Scientific Publication (10 ${ }^{\text {th }}$ Edn): Oxford, pp: 1-714.

4. Dussek JE, Bannister LH, Barry MM et al. (2010) Gray's Anatomy IN: Nervous system. Chapter 12, Churchill Livingston Edinburgh (38 ${ }^{\text {th }}$ Edn) $1795-1812,140,141$, 1810-1812, 144,151-60.

5. Fleischner FG, Sayegh V (1958) Assessment of the size of the liver: roentgenologic considerations. $N$ Engl J Med 259: 271-274. [Crossref]

6. Meilstrup J. Imaging atlas of normal gall bladder and its variants. CRC Press (Taylor \& Francis group) Boca Raton FL: pp: 4.

7. Difiore SH, Mariano (2009) The digestive system, the accessory digestive organs Gallbladder. Organ's section Atlas of histology, Chapter 7 ( $7^{\text {th }}$ Edn), pp: 204-205.

8. Singh IB (2006) Extra hepatic biliary apparatus Gall bladder (Text book of human histology with color atlas), Chapter 16 ( $5^{\text {th }}$ Edn): 259-260.

9. Chapman GB, Chiarodo AJ, Coffey RJ, Wieneke K (1966) The fine structure of mucosal epithelial cells of a pathological human gall bladder. Anat Rec 154: 579-615. [Crossref]

10. Slide5: GallBladder JaydochistoWeb.University.

11. Virchow R, Über das (1857) Epithel der Gallenblasé und übereinenintermediaren Stoffwechsel des Fettes, Virchows Arch. Abt A Pathol Anatfür 574-578.

12. Sheehan HL, Storey GW (1947) An improved method of staining leucocyte granules with Sudan black B. J Pathol Bacteriol 59: 336. [Crossref]

13. Wallraff J, Dietrich KF (1957) [Morphology and histochemistry of the gallbladder in cholelithiasis in man]. Z Zellforsch Mikrosk Anat 46: 155-231. [Crossref]

14. Hopwood D, Kouroumalis E, Milne G, Bouchier IA (1980) Cholecystitis: a fine structural analysis. J Pathol 130: 1-13. [Crossref]

15. High OB (1982) Lipid in: Bancroft JD, Stevens A, et al Chapter 12, Theory and practice of Histological Technique, Churchill Livingstone, Edinburgh, ( $2^{\text {nd }}$ Edn), pp: 217-241.

16. LaMont JT, Smith BF, Moore JR (1984) Role of gallbladder mucin in pathophysiology 

procedures

of gallstones. Hepatology 4: 51S-56S. [Crossref]

17. English M, Hopwood D (1985) Lipid in the human gallbladder mucosa. A histochemical study by light and electron microscopy. J Pathol 146: 333-336. [Crossref]

18. Pearson JP, Foster SN (1987) Mucus glycoprotein content of human cholesterol gallstones. Digestion 36: 132-140. [Crossref]

19. Afdhal NH, Smith BF (1990) Cholesterol crystal nucleation: a decade-long search for the missing link in gallstone pathogenesis. Hepatology 11: 699-702. [Crossref]

20. Jeffrey GP, Shilkin KB, Carrello S, et al (1991) Histological and immunohistochemical study of the gallbladder lesion in primary sclerosing cholangitis. Gut 32: 424-429. [Crossref]

21. Badke A, Böhm B, Schwenk W, Stock W (1993) Histopathological changes of gall bladder and liver parenchyma in symptomatic cholelithiasis. Dtsch Med Wochenschr 118: 809-813. [Crossref]
22. Gilloteaux J, Karkare S, Kelly TR, Hawkins WS (1997) Ultrastructural aspects of human gallbladder epithelial cells in cholelithiasis: production of anionic mucus. Microsc Res Tech 38: 643-659. [Crossref]

23. Csendes A, Burdiles P, Maluenda F, Korn O, Smok G (1998) Histological findings of gall bladder mucosa in 95 control subjects and 80 patients with asymptomatic gal stones. Dig Dis Sci 43: 931-934. [Crossref]

24. Lee KT, Sheen PC, Liu YE (1998) Mucin content in with brown pigment stones or Combination stones with a Brown Periphery. Digestion 59: 660-664. [Crossref]

25. Ganesh IM, Jacyna MR (2007) Mucin histochemistry of stone-containing gall bladder epithelium. Interaction between gall bladder bile and mucosa. J Carcinog 6, 6-29.

26. Stevens A, Bancroft JD, Baylis High OB. Lipid in: et al. (1982) Chapter 12, Theory and practice of Histological Technique. Churchill living stone, Edinburgh. $\left(2^{\text {nd }} \mathrm{Edn}\right)$ : 217-241

Copyright: $(\mathbb{O} 2017$ Pani JP. This is an open-access article distributed under the terms of the Creative Commons Attribution License, which permits unrestricted use, distribution, and reproduction in any medium, provided the original author and source are credited. 